\title{
Capturing the evolution of dealer credit terms related to securities financing and OTC derivatives: some initial results from the new Senior Credit Officer Opinion Survey on Dealer Financing Terms
}

\author{
Matthew J Eichner and Fabio M Natalucci ${ }^{1}$
}

\section{Introduction}

The Federal Reserve recently initiated a new quarterly survey - the Senior Credit Officer Opinion Survey on Dealer Financing Terms (SCOOS) - collecting qualitative information on credit terms and conditions in securities financing and over-the-counter (OTC) derivatives markets. The survey solicits the views of senior credit officers at major dealer firms, in other words those individuals responsible for maintaining a consolidated view of the credit exposures faced by the firm. In several key respects, including its qualitative character and the public dissemination of its results, this new survey is modeled after the Federal Reserve's long-established Senior Loan Officer Opinion Survey on Bank Lending Practices (SLOOS), which provides information about changes in supply and demand conditions for bank loans to businesses and households in the United States. The new survey complements the SLOOS by providing a qualitative picture of changes in credit conditions in the wholesale credit markets that are key conduits for leverage in the financial system.

While there are inherent limitations to a qualitative survey, there are also offsetting strengths. In particular, a survey such as the SCOOS is sufficiently flexible to provide meaningful signals despite the continual evolution of market practices over time, whereas more quantitative approaches constructed around a static set of metrics are vulnerable to financial market developments that render those metrics less relevant or, in the worst case, misleading. ${ }^{2}$

The ScoOs includes a core set of questions that will be posed in identical form each quarter, a practice that will, over time, add a time series dimension to the analysis of the results from the survey. These core questions are organized into three groups. The first group of questions covers credit terms applicable to particular types of counterparties across the entire spectrum of OTC derivatives and securities financing transactions. The second group of questions asks about OTC derivatives trades, differentiating among the underlying asset classes (underlyings) and also between "plain vanilla" derivatives and those that are more highly customized. The third group of questions queries about securities financing trades - that is, lending to clients collateralized by securities - differentiating among different collateral types and recognizing that the terms available to an institution's most favored

1 Board of Governors of the Federal Reserve System.

We appreciate comments and suggestions from Jim Clouse, Bill English, Mike Gibson, Frank Keane, Brian Madigan, Patrick McCabe, Patricia Mosser, Bill Nelson, Michael Palumbo, Pat White, and David Wilcox. The views expressed in this paper are solely the responsibility of the authors and should not be interpreted as reflecting the views of the Board of Governors of the Federal Reserve System or of anyone else associated with the Federal Reserve System.

2 For a discussion of the potential problem, refer to Eichner, M. J., D. L. Kohn, and M. G. Palumbo (2010): "Financial Statistics for the United States and the Crisis: What Did They Get Right, What Did They Miss, and How Should They Change?" Finance and Economics Discussion Series Paper 2010-20. Available at http://www.federalreserve.gov/pubs/feds/2010/201020/201020abs.html. 
clients may differ from those available to average clients. The design of the SCOOS also envisions the periodic inclusion of "special" questions, posed on a one-time basis, to deal with issues of topical interest to policymakers and market participants.

The inaugural Scoos was conducted in June 2010, and focused on the three-month period ending in May 2010. Responses were received from twenty financial institutions that account for almost all of the dealer financing of dollar-denominated securities to nondealers and that are the most active intermediaries in OTC derivatives markets. Overall, responses pointed to some noteworthy developments with respect to counterparty relationships and securities financing over the previous three months. By contrast, the responses indicated little change in terms and conditions prevalent in OTC derivatives markets over this reference period. For instance:

- $\quad$ Survey respondents reported that the amount of resources and attention devoted by dealers to management of concentrated credit exposures to dealers and other financial intermediaries had increased.

- $\quad$ Dealers indicated that they had generally loosened credit terms offered to important groups of clients - including hedge funds and other private pools of capital, insurance companies and other institutional investors, and nonfinancial firms across the entire spectrum of securities financing and OTC derivatives transactions. Dealers also noted that efforts by clients of all these types to negotiate more favorable terms had increased in intensity.

- With respect to OTC derivatives transactions, including those for both plain vanilla and customized derivatives, respondents reported that nonprice terms had changed little across different types of underlyings.

- $\quad$ Responses to questions focused on securities financing suggested an increase in demand for funding high-grade corporate bonds, equities, agency residential mortgage-backed securities (RMBS), and other asset-backed securities (ABS).

- Dealers reported that the volume of mark and collateral disputes with clients remained basically unchanged across counterparty and transaction types. ${ }^{3}$

- Unsurprisingly, responses to "special" questions, which were included in the inaugural survey on a one-time basis to provide perspective on how current credit terms compared with those prevailing at the end of 2006, suggested that current credit terms applicable to all counterparty and transaction types were uniformly more stringent than before the onset of the financial crisis.

This paper describes in greater detail the motivations for the new survey, its design, and the results of the inaugural survey.

\section{Motivations for Developing a New Survey of Dealer Financing Terms}

As noted in the introduction, the new survey is modeled after the SLOOS, which has been conducted by the Federal Reserve in various forms since 1964. The SLOOS asks domestic commercial banks and branches and agencies of foreign banks in the United States about supply and demand conditions in bank credit markets. It has proved to be an important

3 Mark and collateral disputes refer to a claim by one party that is not immediately recognized by the other regarding the valuation of an OTC instrument or the collateral for a securities financing transaction. 
source of information during the recent financial crisis, providing the Federal Reserve with insight into the effects of the crisis on the availability of credit to households and businesses.

The financial crisis, however, also highlighted that a significant volume of credit intermediation had moved outside of the traditional banking sector and emphasized the importance of the "shadow" banking system in the provision of credit to businesses and households and as a conduit for leverage and maturity transformation in the financial system. ${ }^{4}$ Moreover, instruments closely associated with the shadow banking system including OTC derivatives and securities financing transactions - contributed to the buildup of risk prior to the crisis and to the transmission of financial distress across seemingly separate parts of the financial system during the crisis. ${ }^{5}$ Looking back, some policymakers have suggested that they should have perhaps more effectively resisted the tendency towards procyclicality in credit terms, possibly through supervisory action. Similarly, some market participants have questioned whether they, the private sector, should have acted more forcefully to stem the erosion of credit terms which had the effect of enabling greater leverage in the years leading up to the crisis. ${ }^{6}$ However, because little or no systematic data was available on credit terms in wholesale markets, the buildup of risks was not as obvious at the time as it is in hindsight. Clearly, having a better perspective on the amount and sources of leverage employed in the financial system outside of traditional banking institutions is a necessary prerequisite for action, whether by policymakers or market participants, to deal more promptly with such situations in the future.

For these reasons, and given not only its monetary policy responsibilities but also its role in promoting and maintaining the stability of the financial system, the Federal Reserve decided to expand the collection of qualitative information on the availability of credit and leverage beyond the traditional banking sector to the extension of credit by dealers. By providing information on changes in the availability and use of leverage in the financial system, the new survey also has the potential to inform broader macroprudential approaches to the supervision and regulation of financial firms and markets. Indeed, a recent Committee on the Global Financial System (CGFS) study group recommended that central banks and supervisors consider the value of regularly conducting qualitative surveys focused on collateral haircuts, margin terms, and other topics covered extensively in the ScOOS, arguing that such surveys are potentially important tools for macroprudential authorities. ${ }^{7}$ Already several projects are underway - involving not only the Federal Reserve but also regulators in other jurisdictions and multilateral agencies - that focus on understanding and tracking the aggregate amount of leverage in the financial system. The SCOOS should provide useful input to such efforts by helping to identify market developments that might call for a more focused collection of detailed quantitative information.

4 Refer to Pozsar, Z., T. Adrian, A. Ashcraft, and H. Boesky (2010): "Shadow Banking," Federal Reserve Bank of New York Staff Reports No. 458. Available at http://www.newyorkfed.org/research/staff reports/sr458.html.

5 Of course the proximate causes of the crisis go well beyond the particular mechanisms utilized to lever exposures, including those prevalent in the shadow banking system. For example, there is little doubt that lax underwriting standards, overreliance on public credit ratings, and poor discipline around the marking of positions were significant factors. For further discussion of underlying causes of the crisis, refer to "Policy Statement on Financial Market Developments," President's Working Group on Financial Markets, March 2008. Available at www.treasury.gov/resource-center/fin-mkts/Documents/pwgpolicystatemktturmoil 03122008.pdf.

6 Refer to "The Role of Valuation and Leverage in Procyclicality," published by the Committee on the Global Financial System, for a discussion of sources of procyclicality in the financial system prior to the crisis. Available at http://www.bis.org/publ/cgfs34.pdf.

7 Refer to "The Role of Margin Requirements and Haircuts in Procyclicality," published by the Committee on the Global Financial System, for further discussion of the procyclicality of margin requirements and haircuts. Available at http://www.bis.org/publ/cgfs36.pdf. 
While there are inherent limitations to a qualitative survey, this approach also has certain advantages. Dealer credit terms applicable to counterparties such as hedge funds, institutional investors, and corporate clients involve a large number of parameters, many of which vary across both counterparties and products. For example, collateral and margin terms distinguish between initial margin requirements and transfers required in response to market movements, with each set of parameters generally depending on both the type of product and the strength and nature of the client relationship. Consequently, any effort to describe the resulting vector of credit terms quantitatively would have to not only deal with these multiple dimensions but also do so in a manner that does not quickly become out of date as a result of changes in market practices. In contrast, a qualitative survey can provide a strong directional indication as to whether terms have broadly become more or less stringent without requiring a quantitative reporting of the specific terms and market conventions that may be driving the changes at a particular time.

\section{The Design of the New Survey}

The SCOOS is intended to be sent quarterly to the twenty U.S. and foreign dealers that, in the aggregate, account for almost all of the dealer financing of dollar-denominated securities to nondealers and that are the most active intermediaries in OTC derivative instruments. The survey is directed to senior credit officers who maintain a consolidated perspective regarding the activities that are the focus of the survey, irrespective of the business area or areas in which they are conducted and the legal entity in which they are booked. ${ }^{8}$

The ScOOS includes a core set of 47 questions designed to collect qualitative information on the stringency of credit terms, credit availability and demand across the entire range of securities financing and OTC derivatives transactions, and the evolution of market conditions and practices applicable to such activities. The core questions, organized in three groups, include both retrospective items, focusing on changes in market conditions over the prior three months, and prospective items, focusing on expectations for the coming three months. The first group of questions covers the credit terms applicable to particular types of counterparties - including dealers and other financial intermediaries, hedge funds and other private pools of capital, institutional investors such as insurance companies and pension funds, and corporate clients - across the entire spectrum of transactions. ${ }^{9}$

The second group of questions focuses on OTC derivatives trades, differentiating among different underlyings (foreign exchange, interest rates, equities, credit, commodities, and total return swaps referencing nonsecurities) and also between plain vanilla derivatives and those that are more highly customized. ${ }^{10}$

8 The activities that are the focus of the ScoOs may be conducted by large financial institutions through multiple business units and legal entities. For example, a significant volume of securities financing may be conducted from a prime brokerage platform. Nevertheless, other similar activities, perhaps with clients other than hedge funds, also occur on trading desks with mandates that include making markets in the securities being financed or on centralized securities financing desks. In a similar vein, OTC derivatives transactions may occur on dedicated equity or interest rate derivatives desks that are primarily engaged in derivatives transactions, but can also flow through businesses like corporate credit and commodities that trade both derivatives and the related cash instruments.

9 Questions include changes over the past three months in the stringency of price terms (e.g., financing rates) and nonprice terms (e.g., haircuts, maximum maturity, covenants, cure periods, cross-default provisions, and other documentation features), reasons for changes, intensity of efforts to negotiate more favorable terms, and expectations for price and nonprice term changes over the next three months.

10 Questions include changes over the past three months in nonprice terms and the volume of mark and collateral disputes with clients. 
The third group of questions queries about securities financing transactions - that is, lending to clients collateralized by securities - differentiating among different collateral types (highgrade corporate bonds, equities, agency RMBS, and other ABS) and recognizing that the terms available to an institution's most favored clients may differ from those available to average clients. ${ }^{11}$

Of note, with regard to OTC derivatives and securities financing transactions, questions are posed about changes in the prevalence of mark and collateral disputes with clients as an increase in such disputes may suggest emerging operational stresses or other risk issues. Indeed, during the recent financial crisis, an uptick in mark and collateral disputes proved a good leading indicator of stress within the financial system. In addition, in the section focused on securities financing transactions, qualitative assessments are solicited regarding market liquidity and functioning with respect to each specific type of collateral. A final question invites respondents to comment on other issues of particular interest not addressed elsewhere in the survey.

In addition to these core questions, topical questions can be added each quarter, as is done in the SLOOS, to deal with issues of particular immediate concern and relevance.

\section{Implementation of the New Survey}

Implementation of the new survey began with an extensive process of consultation with market participants by staff members at the Federal Reserve Board and Federal Reserve Bank of New York (FRBNY). The purpose of these discussions was two-fold: First, the staff sought to understand the degree to which the survey under consideration might be useful to market participants. Second, specific feedback was solicited concerning the broad content of a draft survey instrument as well as the optimal framing of specific questions. While indicating significant support for the survey on the part of market participants, the meetings suggested a number of respects in which the draft survey could be improved. For example, the draft survey did not sufficiently distinguish between the set of credit terms relevant for other financial intermediaries and those applicable to clients. These early discussions also highlighted that the draft survey was too detailed in asking about some credit terms, but not sufficiently detailed in collecting information in other areas. The incorporation of feedback from these conversations into the final draft of the survey is described in greater detail in the final Federal Register notice published by the Federal Reserve on March 30, 2010. ${ }^{12}$

To facilitate the ongoing administration of the survey once the design and approval phases were complete, the Statistics unit at the FRBNY designed and constructed a secure web interface, similar to systems that they had developed for other data collection efforts. The system provides significant functionality to both respondents and Federal Reserve staff. From the perspective of the Federal Reserve, the system allows for the generation of reports in spreadsheet formats at the push of a button.

In order to make the results available to market participants, central banks, supervisors, and multilateral organizations as a common benchmark for assessing trends in the availability and use of leverage in the financial system, the survey is made available to the public on the Federal Reserve Board's website. However, individual firm responses to the survey are not

11 Questions include changes over the past three months in price and nonprice terms, the amount of vendor financing (that is, financing provided on more favorable terms for securities that were underwritten by the respondent institution), clients' demand for funding, volume of mark and collateral disputes with clients, and liquidity and functioning of the markets for the underlying collateral.

12 Refer to http://www.federalreserve.gov/reportforms/formsreview/FR2034 20100330 ffr.pdf. 
published to allow frank and complete responses on the part of the surveyed firms, without raising concerns about revealing sensitive proprietary information.

\section{Responses to the June 2010 SCOOS $^{13}$}

The inaugural Scoos survey was conducted during the period from May 24, 2010, to June 4, 2010, and the reference period for the core questions of the survey was March 2010 through May 2010. In addition to the core questions, special questions were included asking survey respondents to characterize the current stringency of credit terms relative to the end of 2006, before the onset of the crisis. These questions were intended to provide a benchmark level for interpreting a survey that is focused on changes yet was being administered for the first time. ${ }^{14}$ As noted in the introduction, responses pointed to some noteworthy developments with respect to counterparty relationships and securities financing over the previous three months, but the responses indicated little change in the terms and conditions prevalent in OTC derivatives markets over this reference period.

Although the survey encompasses essentially all of the financial institutions active in the relevant areas across the entire range of securities financing and OTC derivatives transactions, some caution in interpreting the results is warranted due to the fairly small number of firms surveyed and the fact that the modal responses to many questions indicated that credit terms and conditions were generally little changed over the past three months. With a sample of just twenty firms (and some firms not active in all areas), some apparent adjustments in lending posture may reflect a change in the behavior or perceptions of only a few firms. Over time, as additional surveys allow a time series dimension to be incorporated into the analysis, the staff should develop a better sense for when reported changes are likely to be economically important.

\section{Counterparty Types}

Dealers and other financial intermediaries. More than one-half of the respondents indicated that the amount of resources and attention devoted by dealers to management of concentrated exposures to dealers and other financial intermediaries had increased somewhat over the past three months, with the remainder characterizing their focus as unchanged. The vast majority of respondents, however, reported that the volume of mark and collateral disputes with dealers and other financial intermediaries had remained basically unchanged over the past three months. ${ }^{15}$

13 Tables with the distribution of individual responses are available on the Federal Reserve Board website at http://www.federalreserve.gov/econresdata/releases/scoos.htm.

14 Like the core survey, the special questions focused separately on credit terms applicable to particular counterparty types across the entire spectrum of transactions, to OTC derivatives trades, and to securities financing transactions.

15 The section on exposure to dealers and other financial intermediaries is structured somewhat differently from the sections dealing with clients of various types. Conversations with market participants indicated that the individual price and nonprice terms - ranging from financing rates to haircuts, collateral requirements, limits on maturity and documentation provisions - are very important in the process of dealers managing exposures to clients, but are far less relevant in the management of exposure to other dealers. In dealer-to-dealer interactions, terms are essentially very standardized and are not subject to regular fine adjustments. Thus, as seen during the financial crisis, the critical decision for a dealer in managing exposure to another dealer is a binary choice about whether to continue transacting or not. For this reason, the questions dealing with dealer counterparties focus only on the amount of resources and attention devoted to monitoring other dealers, as well as the prevalence of mark and collateral disputes which occur disproportionately among dealers. For 
Hedge funds, private equity firms, and other similar private pools of capital. Responses with respect to credit terms applicable to hedge funds, private equity firms, and other similar private pools of capital indicated that, across several dimensions, dealers had provided somewhat more favorable terms over the past three months. A small net fraction of respondents had eased price terms, which include, most importantly, financing rates. ${ }^{16}$ Onefourth of respondents, on balance, reported having loosened nonprice terms, which include haircuts, maximum maturity, covenants, cure periods, cross-default provisions, and other documentation features. According to the survey, the predominant reasons cited for loosening price and nonprice terms offered to hedge fund counterparties over the past three months were more aggressive competition from other institutions, improvement in the current or expected financial strength of counterparties, and improvement in general market liquidity and functioning. ${ }^{17}$ In characterizing their interactions with hedge fund counterparties, almost two-thirds of dealers indicated that the intensity of efforts by these counterparties to negotiate more favorable price and nonprice terms had increased over the past three months. Of note, one-fourth of respondents reported a considerable increase in the intensity of these efforts. Looking forward over the next three months, a small net fraction of dealers expected somewhat tighter price and nonprice terms, with more than one-half of survey respondents anticipating terms to remain basically unchanged.

Insurance companies, pension funds, and other institutional investors. Responses to questions about credit terms for insurance companies, pension funds, and other institutional investors showed similar but more muted trends. Small net fractions of dealers indicated that they had loosened both price and nonprice terms over the past three months for such counterparties. The three factors that were reported to have exerted the greatest influence on dealers' policies were improvement in the current or expected financial strength of counterparties, improvement in general market liquidity and functioning, and more aggressive competition from other institutions. More than one-third of respondents indicated that the intensity of efforts by insurance companies, pension funds, and other institutional investors to negotiate more favorable price and nonprice terms had increased over the past three months. Looking forward over the next three months, more than one-half of dealers anticipated that price and nonprice terms would remain basically unchanged.

Nonfinancial corporations. The responses to questions about credit terms applicable to nonfinancial corporations also suggest a loosening over the past three months. One-fourth of dealers, on balance, reported a loosening of price terms offered to these counterparties, while a small net fraction of respondents indicated that they had eased nonprice terms. The most important reasons cited for the loosening in credit terms were broadly consistent with those for other counterparty types: Respondents pointed to improvement in general market liquidity and functioning, more aggressive competition from other institutions, and improvement in the current or expected financial strength of counterparties. Dealers reported some pressure on terms from nonfinancial counterparties, with one-half of survey

other types of counterparties, the survey poses more granular questions focusing on particular terms that function as "dials" that dealers can adjust to actively manage their exposures.

16 Consistent with the language used in the SLOOS, for questions that ask about credit terms, reported net percentages equal the percentage of institutions that reported tightening terms ("tightened considerably" or "tightened somewhat") minus the percentage of institutions that reported loosening terms ("loosened considerably" or "loosened somewhat"). For questions that ask about demand, reported net fractions equal the percentage of institutions that reported increased demand ("increased considerably" or "increased somewhat") minus the percentage of institutions that reported decreased demand ("decreased considerably" or "decreased somewhat").

17 Consistent with the longstanding SLOOS practice, an ordinal ranking of reasons for loosening or tightening is produced by adding the number of respondents characterizing each reason as "very important" to the number characterizing the reason as "somewhat important" and then sorting the sums in descending order. 
respondents noting that the intensity of efforts to negotiate more favorable terms had increased over the past three months. Looking forward, almost one-fifth of dealers, on net, expected a further loosening of the price and nonprice terms under which they transact with nonfinancial corporations.

\section{Over-the-Counter Derivatives}

Overall, the responses to the questions dealing with OTC derivatives trades suggested little change over the past three months in terms for plain vanilla and customized derivatives as well as in the volume of mark and collateral disputes with clients across the various underlyings - foreign exchange, interest rates, equities, credit, commodities, and total return swaps referencing nonsecurities (such as bank debt and whole loans). ${ }^{18}$

\section{Securities Financing}

The most important trend evident from the responses to questions dealing with securities financing related to demand for funding. ${ }^{19}$ Survey respondents indicated that, on net, demand for funding had generally increased over the past three months. Of note, among dealers that offer such financing, one-third reported an increase in demand for funding of agency RMBS and one-half reported an increase in demand for funding of other ABS, on net.

Broad trends regarding changes in terms were more difficult to discern from the dealer responses. However, certain specific changes in terms were identified by several dealers. For example, small net fractions of respondents reported having increased financing rates at which high-grade corporate bonds are funded for both average and most favored clients over the past three months. By contrast, small net fractions of dealers reported lengthening the maximum maturity over which they would fund equities for both average and most favored clients. In the case of agency RMBS, small net fractions of survey respondents indicated that they had eased a couple of terms (maximum maturity and haircuts) for both average and most favored clients. On net, small fractions of dealers active in other ABS reported a reduction in haircuts applicable to both average and most favored clients.

Questions about liquidity and market functioning for various types of collateral funded through repurchase agreements and similar secured financing transactions, which are included in this section of the survey, generally suggested no major change in the views of senior credit officers. About one-fourth of respondents, however, indicated that liquidity and functioning in the market for other ABS had deteriorated over the past three months. There was no indication of an increase in collateral and mark disputes with clients for funding of any collateral, including other ABS.

\section{Special Questions on the Stringency of Credit Terms Relative to the End of 2006}

Not surprisingly, responses to the special questions pointed to significantly tighter credit terms across counterparty and transaction types relative to the end of 2006. All respondents but one characterized credit terms applicable to hedge fund counterparties as currently tighter than in the reference period. A significant majority of respondents also reported tighter

18 Market practices with respect to OTC derivatives require a more extensive vector of terms to adequately capture all the dimensions across which terms can change. But this granularity makes it more difficult to distill broad trends from the responses in this section.

19 In the SCOOS, securities financing includes lending to clients collateralized by high-grade corporate bonds, equities, agency RMBS, and other ABS. 
credit terms for insurance companies, pension funds, and other institutional investors. By contrast, about one-third of dealers noted that the current stringency of credit terms applicable to nonfinancial corporations was basically unchanged relative to the end of 2006 . In general, the vast majority of dealers reported tighter credit terms relative to the end of 2006 with regard to both OTC derivatives and securities financing transactions.

\section{Conclusion}

The inaugural ScoOS raised no significant unexpected technical or methodological issues, and yielded responses that were broadly consistent with the limited available evidence regarding trends in the relevant markets during the reference period. Thus, early indications support the proposition that the survey will be a useful addition to the toolkit available to policymakers and members of the public seeking to better understand the amounts and sources of leverage utilized in the financial system. This information will be particularly useful for those working on macroprudential approaches to the supervision and regulation of financial firms and markets. As the survey's core questions are posed repeatedly in the coming quarters, the additional time series dimension should increase the possibilities for analyzing survey results, both to allow further validation of the signals coming from the scoos against other sources of information and to inform analysis of the substantive issues. 